\title{
Demographic Survey of Married Women in Barau Dikko Specialist Hospital Kaduna State
}

\author{
Mataimaki Benard Joel \\ Department of Statistics, Faculty of Physical Science, Ahmadu Bello University, Zaria, Nigeria \\ Email address: \\ manjoello@yahoo.com \\ To cite this article: \\ Mataimaki Benard Joel. Demographic Survey of Married Women in Barau Dikko Specialist Hospital Kaduna State. International Journal of \\ Data Science and Analysis. Vol. 4, No. 1, 2018, pp. 6-12. doi: 10.11648/j.ijdsa.20180401.12
}

Received: October 20, 2017; Accepted: November 15, 2017; Published: January 29, 2018

\begin{abstract}
This study undertakes a demographic survey of married women in Barau Dikko Specialist Hospital. A sample of 160 married women going for maternity (Antenatal and Postnatal care) were administered questionnaires. The analysis reveals that the mean age at menarche is 13 years; mean age of women at last delivery is 31 years and the average duration of breastfeeding for the women's first child is 14 months. The analysis also shows that the duration of breast feeding for the women's first child is 14 months. This research made use of correlation analysis to investigate if there is a relationship between breastfeeding and postpartum amenorrhea. We observed that there is a perfect positive correlation of 0.35 between the duration of postpartum amenorrhea (PPA) after the first life birth (months) and the duration of breastfeeding for the last but one life birth (months) at 1\% level of level of significance. Also, it was observed that there is no relationship of 0.12 between the duration of postpartum amenorrhea (PPA) after the first life birth (months) and duration of breastfeeding for the first life birth (months).
\end{abstract}

Keywords: Correlation Analysis, Family Planning, Breastfeeding and Postpartum Amenorrhea

\section{Introduction}

Menarche is the first menstrual period or first menstrual bleeding in the females of human beings from both social and medical perspectives. It is often considered the central event of female puberty, as it signals the possibility of fertility. Timing of menarche is influenced by both genetic and environmental factors, especially nutritional status. The age at which girls begin to menstruate varies widely and may be influenced notably by the percentage of body fat. Anywhere from 10.8 years old to 14.6 years old is considered normal, although the average age of menarche has declined over the last century, but the magnitude of the decline and the factors responsible remain subjects of contention. Menarche in a girl is a sign of growing up and becoming a woman, which means that she could get pregnant in the month before her first period starts.

Couples have been using many different methods for child spacing or family planning in order to control fertility and it makes it evident that the ability to regulate their fertility is possible. The mechanism to reduce the likelihood of pregnancy or child birth is commonly used as part of family planning (birth control) which is a way to help couple be able to space their family and to limit the number in the way that they desire or it is giving birth by choice and not chance. Also it is the spacing of child birth until such a time that is needed, and it is for the couples to determine what the right number is for them. However, child spacing varies from one family to another.

Amenorrhea is a menstrual condition characterized by absent menstrual periods for more than three monthly menstrual cycles. There are two types of amenorrhea, primary and secondary.

Primary amenorrhea is delayed menarche (the first menstrual period) and is defined as the absence of menarche by age 16 with otherwise normal pubertal development (development of breast or pubic hair), absence of menarche by age 14 with delayed pubertal development or absence of menarche two years after puberty is otherwise completed. Family history should be taken into consideration in any adolescent with primary amenorrhea; mothers who started to menstruate late will often have daughters who also menstruate late.

Secondary amenorrhea is the absence of menstruation after 
menarche has taken place. Although it is not uncommon for menstrual period to be irregular during early adolescent, periods usually become regular within 18 months after one. After that time, it is considered abnormal for an adolescent to miss three consecutive periods. This problem is seen in about $1 \%$ of women of reproductive age.

An abortion is defined as the termination of a pregnancy by the removal or expulsion from the uterus of a fetus/embryo, resulting in its death. An abortion can occur spontaneously due to complications during pregnancy or can be induced, in human and other species. The term abortion most commonly refers to the induced abortion of a human pregnancy, while spontaneous abortions are usually termed miscarriages.

Postpartum amenorrhea is a biological variable associated with each conception regardless of its outcome. It depends on a number of factors which may vary from woman to woman in a population and for a woman depending on age, marital duration of pregnancies, nutritional status and practice of breast feeding etc. PPA in women varies from around a month to more than a year. The length of PPA depends on the intensity and length of breast feeding. Duration of PPA varies from community to community with respect to some socialeconomic and demographic characteristics of mothers.

Lactation is the secretion of milk by the mammary glands of the breasts, which usually begins at the end of pregnancy. A fluid called colostrums is secreted before the milk is produced both secretions are released in response to the sucking action of the infant on the nipple. Lactation is controlled by hormones (prolactin oxytocin), it stops when the baby is no longer fed at the breast. The process occurs in all female mammals, and in human it is commonly referred to as breast feeding or nursing.

Lactational Amenorrhea (LA) is the interval between birth of a child and subsequent return of menses; it's an important regulator of fertility in developing countries. Breastfeeding in particular, exclusive breast feeding has a significant contraceptive effect by postponing the return of ovulation after the birth of a child.

\section{Method}

\subsection{Barau Dikko Specialist Hospital (BDSH)}

The Barau Dikko Specialist system is a non-profit health care in Kaduna, Nigeria. It is a State owned hospital under the State Ministry of health. The hospital works closely with the State government to bring compassion to all its endeavors and to help meet the health needs of the community it serves. The hospital as "New General Hospital" was officially opened in 1985 by the then Nigeria President General Muhammadu Buhari. It was later renamed in 1999 as "Barau Dikko Specialist Hospital" after the death of late Barau Dikko, the first medical practitioner in the north. The line with the general corporate administrative set-up, the BDSH reports to the State Ministry of health through the Chief Medical Director who is in charge of the entire hospital, the hospital Director who is in charge of administration and the matron in charge of nursing staff and assisting the director in running the hospital.

The hospital has several departments which includes Surgeon, internal medicine, ENT (ear, nose, throat), pediatrics, radiology, physiotherapy, pharmacy, medical record, immunization, counseling (for HI) casualty, family planning etc. There are also three (3) laboratories which are Hematology, microbiology and chem.-path. A total number of 250 beds were spread all over the male and female wards, pediatric and amenity rooms. The hospital has two (2) operation theatres, a functional mortuary, mechanize laundry, medical shop/pharmacy, 24 hours ambulances, house officers (house man ship training) and also provide consultancy services.

\subsection{Method of Data Collection}

The questionnaires were prepared to suit the number of sample, covering personal and demographic information such as number of a woman, age at menarche, age at effective marriage etc, and some operational definitions of the duration of postpartum amenorrhea, lactation. Data are going to be analyzed using the statistical package of social science (SPSS).

As a result of these, one hundred and sixty questionnaires were prepared and one hundred and forty four questionnaires were returned. So therefore, 144 questionnaires were used for the survey. All women were subjected to an interview questionnaire designed to reveal; age at menarche, age at first delivery, interval between effective marriage and first life birth, the duration of postpartum amenorrhea for both first, last but one and last life birth, the adopted contraceptive method, the duration of breastfeeding for both first, last but one and last life birth.

\subsection{The Model}

\section{THE CHI-SQUARE $\left[\chi^{2}\right]$ DISTRIBUTION}

The chi-square $\left(\chi^{2}\right)$ test is one of the simplest and most widely used non-parametric test in the statistical work. The symbol is the Greek letter chi. The chi-square distribution was discovered by Helmert in 1875 and was rediscovered independently by Karl Pearson in 1990. The quantity describes the magnitude of the discrepancy between theory and observation. It is defined as:

$$
\chi^{2}=\frac{\sum_{i=1}^{n}\left(0_{i}-E_{i}\right)^{2}}{E_{i}}
$$

Where 0 refers to the observed frequency; and E refers to the expected frequency.

If $\chi^{2}=0$, the observed and theoretical frequencies agree exactly; while if $\chi^{2}>0$, they do not agree exactly. The larger the value of $\chi^{2}$, the greater the discrepancy between the observed and expected frequencies.

The chi-square distribution has one parameter $\mathrm{v}$, the number of degree of freedom. As in case of t-distribution there is a distribution for each different number of degree of freedom. 
For very small number of degrees of freedom, the chi-square distribution is severely skewed to the right. As the number of the degree of freedom increase, the curve rapidly becomes more symmetrical. For large value of $\mathrm{v}$ the chi-square distribution is closely approximated by the normal curve.

The chi-square is a probability distribution and the total area under the curve in each chi-square distribution is 1.0. Like the t-distribution so many different chi-square distributions are possible that is not practical to construct a table that illustrates the area under the curve for all possible value of the area.

\subsection{Correlation Analysis}

Correlation is a statistic technique used for analyzing the behavior of two or more variables. It expresses the relationship between the variables through a relative measure change and hence the units in which the variables are expressed are not considered in correlation analysis. It also measures the degree as well as the direction of the sympathetic movement in two or more variables.

The degrees are expressed by coefficient which range between -1 to +1 and the direction of change is indicated by the positive/negative signs, refers to the sympathetic movements in the same direction signs, and refers to the sympathetic movement in the same direction which refers to movements in the same direction which refers to movement in the opposite direction.

The cogent thing is that correlation is used to measure the strength of the association between quantitative variables under this concept of the degree of relationship between the variables is measured by using correlation coefficient denoted by "r"

$$
r=\frac{n \sum x y-\sum x \sum y}{\sqrt{\left[n \sum x^{2}-\left(\sum x\right)^{2}\right]\left[n \sum y^{2}-\left(\sum y\right)^{2}\right]}}
$$

Where $\mathrm{x}$ is the independent variable, $\mathrm{y}$ is the dependent variable and $n$ is the number of observation.

It varies from $r=0$ which suggest there is no relationship existing between the variables, to $r=1$ which suggest a perfect linear correlation or $\mathrm{r}=-1$ which suggests a perfect negative linear correlation. The correlation coefficient (r), is usually reported in terms of its square $\left(\mathrm{r}^{2}\right)$, interpreted as percent of variance.

A correlation of 1 means there is a perfect positive linear relationship between the two variables.

A correlation of -1 means that there is a perfect negative relationship between the two variables.

A correlation of 0 means there is no linear relationship between the two variables. However, correlation is rarely o,$1,+1$. Some real data show a moderately high relationship.

\section{Result}

The statistical analysis is aimed at data collection with regards to the relationship between breast feeding and postpartum amenorrhea among women in Barau Dikko Specialist Hospital and married women. The chapter sectionalized into presentation of the demographic variables of the respondents, an assessment of the relationship between breast feeding and postpartum amenorrhea among women, test of the study's hypothesis and an interpretation of the result.

\subsection{Presentation of the Respondents' Demographic Characteristics}

Among the demographic characteristics of the women selected for the study are the level of education, religion, ethnic group, and occupation of the women and that of their husbands. These variables are presented in frequencies and percentages respectively in the section.

Table 1. Distribution of respondent with respect to if they experienced any abortion during the interval between marriage and first live birth?

\begin{tabular}{lllll}
\hline Have you had any abortion? & Frequency & Percent & Valid Percent & Cumulative Percent \\
\hline No response & 1 & 0.7 & 0.7 & 0.7 \\
Yes & 11 & 7.6 & 7.6 & 8.3 \\
No & 132 & 91.7 & 91.7 & 100.0 \\
TOTAL & 144 & 100.0 & 100.0 & \\
\hline
\end{tabular}

The table 1 shows that $0.7 \%$ of the respondent did not respond to this question, $7.6 \%$ of them had abortion and $91.7 \%$ of them had no abortion between marriage and first live birth.

Table 2. Distribution of respondent with respect to the use of family planning?

\begin{tabular}{lllll}
\hline Do you use family planning? & Frequency & Percent & Valid Percent \\
\hline No response & 2 & 1.4 & 1.4 & Cumulative Percent \\
Yes & 112 & 77.8 & 77.8 & 7.4 \\
No & 30 & 20.8 & 20.8 & 19.2 \\
TOTAL & 144 & 100.0 & 100.0 \\
\hline
\end{tabular}

Table 2 reveals that about $77.8 \%$ of the women use family planning while $20.8 \%$ do not use family planning. 
Table 3. If yes, what is the device adopted.

\begin{tabular}{lllll}
\hline Oral Contraceptive Pill & Frequency & Percent & Valid Percent & Cumulative Percent \\
\hline No & 107 & 74.3 & 74.3 & 74.3 \\
Yes & 37 & 25.7 & 25.7 & 100.0 \\
Total & 144 & 100.0 & 100.0 & \\
\hline
\end{tabular}

The table 3 shows that $25.7 \%$ of the women use Oral Contraceptive Pill for family planning while the other respondents do not use it.

Table 4. Responses to the use of Injection Contraceptive.

\begin{tabular}{lllll}
\hline Injection Contraceptive & Frequency & Percent & Valid Percent & Cumulative Percent \\
\hline No & 116 & 80.6 & 80.6 & 80.6 \\
Yes & 28 & 19.4 & 19.4 & 100.0 \\
Total & 144 & 100.0 & 100.0 & \\
\hline
\end{tabular}

The table 4 shows that $19.4 \%$ of the women use the Injection Contraceptive for family planning while the others do not use it.

Table 5. Responses to the use of IUCD Intrauterine.

\begin{tabular}{lllll}
\hline IUCD Intrauterine & Frequency & Percent & Valid Percent & Cumulative Percent \\
\hline No & 111 & 77.1 & 77.1 & 77.1 \\
Yes & 33 & 22.9 & 22.9 & 100.0 \\
Total & 144 & 100.0 & 100.0 & \\
\hline
\end{tabular}

Table 5 shows that $22.9 \%$ of the women use IUCD Intrauterine for family planning while $77.1 \%$ of the women do not use it.

Table 6. Resonses to the use of Spermicidal.

\begin{tabular}{lllll}
\hline Spermicidal & Frequency & Percent & Valid Percent & Cumulative Percent \\
\hline No & 142 & 98.6 & 98.6 & 98.6 \\
Yes & 2 & 1.4 & 1.4 & 100.0 \\
Total & 144 & 100.0 & 100.0 & \\
\hline
\end{tabular}

The table 6 shows that only $1.4 \%$ of the women use spermicidal for family planning.

Table 7. Responses to the use of Natural Family Planning.

\begin{tabular}{lllll}
\hline Natural Family Planning & Frequency & Percent & Valid Percent & Cumulative Percent \\
\hline No & 115 & 79.9 & 79.9 & 79.9 \\
Yes & 29 & 20.1 & 20.1 & 100.0 \\
Total & 144 & 100.0 & 100.0 & \\
\hline
\end{tabular}

Table 7 shows that $20.1 \%$ of the women use natural family planning while $79.9 \%$ do not use the natural family planning.

Table 8. Distribution of respondent with respect to recommendation of family planning?

\begin{tabular}{lllll}
\hline Do you recommend family planning? & Frequency & Percent & Valid Percent & Cumulative Percent \\
\hline Yes & 131 & 91.0 & 91.0 & 91.0 \\
No & 13 & 9.0 & 9.0 & 100.0 \\
TOTAL & 144 & 100.0 & 100.0 & \\
\hline
\end{tabular}

The table 8 shows that $9.0 \%$ do not recommend family planning while $91.0 \%$ recommend family planning.

\subsection{Descriptive Statistics}

The descriptive analysis shows the mean distribution of age at menarche, age at last delivery, interval between marriage and first live birth, duration of postpartum amenorrhea after first live birth, duration of postpartum amenorrhea after last but one live birth, duration of postpartum amenorrhea after last live birth, duration of breastfeeding for the first live birth, duration of breastfeeding for the last but one live birth, e.t.c. 
Table 9. Descriptive Statistics of the survey.

\begin{tabular}{|c|c|c|c|c|c|}
\hline \multicolumn{6}{|l|}{ Descriptive Statistics } \\
\hline Variables & $\mathbf{N}$ & Minimum & Maximum & Mean & $\begin{array}{l}\text { Std. } \\
\text { Deviation }\end{array}$ \\
\hline AGE AT MENARCHE & 144 & 10.00 & 30.00 & 13.8681 & 1.97625 \\
\hline AGE AS AT LAST DELIVERY & 144 & .00 & 47.00 & 31.3403 & 7.25670 \\
\hline INTERVAL BETWEEN MARRIAGE AND FIRST LIFE BIRTH (MONTHS) & 144 & .00 & 60.00 & 12.5417 & 8.45132 \\
\hline $\begin{array}{l}\text { DURATION OF POST PARTUM AMENORRHEA (PPA) AFTER THE FIRST LIFE } \\
\text { BIRTH (MONTHS) }\end{array}$ & 144 & .00 & 36.00 & 6.2083 & 5.82120 \\
\hline DURATION OF PPA AFTER LAST BUT ONE LIFE BIRTH (MONTHS) & 144 & .00 & 48.00 & 6.4306 & 7.63563 \\
\hline DURATION OF PPA AFTER LAST BIRTH (MONTHS) & 144 & .00 & 60.00 & 7.9861 & 10.76902 \\
\hline DURATION OF BREAST FEEDING FOR YOUR FIRST CHILD & 144 & .00 & 36.00 & 14.0903 & 5.75965 \\
\hline DURATION OF BREAST FEEDING FOR THE LAST BUT ONE CHILD (MONTHS) & 144 & .00 & 24.00 & 13.0069 & 6.00174 \\
\hline DURATION OF BREAST FEEDING FOR THE LAST CHILD (MONTHS) & 144 & .00 & 30.00 & 13.4028 & 6.06644 \\
\hline Valid N (listwise) & 144 & & & & \\
\hline
\end{tabular}

From table 9, we observed that the mean age at menarche is 13.87 years. The mean age at last delivery of the women was found to be 31.34 years. The mean interval between marriage and first live birth was found to be 12.54 months.

The mean duration of postpartum amenorrhea after first live birth was found to be 6.20 months, the mean duration of PPA for the last but one child is 6.43 months, mean duration of postpartum amenorrhea after the last live birth is 7.99 months. The mean duration of breastfeeding for the first child is 14.09 months, the mean duration of breastfeeding for the last but one child is 13.00 months; the mean duration of breastfeeding for the last child is 13.40 months.

\subsection{Data Analysis}

Correlation Analysis

Table 10. Correlation Analysis.

\begin{tabular}{|c|c|c|c|}
\hline VARIABLES & & $\begin{array}{l}\text { AGE AT } \\
\text { MENARCHE }\end{array}$ & $\begin{array}{l}\text { DURATION OF POST PARTUM } \\
\text { AMENORRHEA (PPA) AFTER THE } \\
\text { FIRST LIFE BIRTH (MONTHS) }\end{array}$ \\
\hline \multirow{3}{*}{ AGE AT MENARCHE } & Pearson Correlation & 1 & .116 \\
\hline & Sig. (2-tailed) & & .166 \\
\hline & $\mathrm{N}$ & 144 & 144 \\
\hline \multirow{3}{*}{$\begin{array}{l}\text { DURATION OF POST PARTUM AMENORRHEA } \\
\text { (PPA) AFTER THE FIRST LIFE BIRTH (MONTHS) }\end{array}$} & Pearson Correlation & .116 & 1 \\
\hline & Sig. (2-tailed) & .166 & \\
\hline & $\mathrm{N}$ & 144 & 144 \\
\hline \multirow{3}{*}{$\begin{array}{l}\text { DURATION OF PPA AFTER LAST BUT ONE LIFE } \\
\text { BIRTH (MONTHS) }\end{array}$} & Pearson Correlation & .118 & $.781^{* *}$ \\
\hline & Sig. (2-tailed) & .160 & .000 \\
\hline & $\mathrm{N}$ & 144 & 144 \\
\hline \multirow{3}{*}{$\begin{array}{l}\text { DURATION OF BREAST FEEDING FOR YOUR } \\
\text { FIRST CHILD }\end{array}$} & Pearson Correlation & .122 & .121 \\
\hline & Sig. (2-tailed) & .145 & .150 \\
\hline & $\mathrm{N}$ & 144 & 144 \\
\hline \multirow{3}{*}{$\begin{array}{l}\text { DURATION OF BREAST FEEDING FOR THE LAST } \\
\text { BUT ONE CHILD (MONTHS) }\end{array}$} & Pearson Correlation & .139 & $.348^{* *}$ \\
\hline & Sig. (2-tailed) & .098 & .000 \\
\hline & $\mathrm{N}$ & 144 & 144 \\
\hline
\end{tabular}

Table 10. Continued.

\begin{tabular}{|c|c|c|c|c|}
\hline VARIABLES & & $\begin{array}{l}\text { DURATION OF PPA } \\
\text { AFTER LAST BUT ONE } \\
\text { LIFE BIRTH } \\
\text { (MONTHS) } \\
\end{array}$ & $\begin{array}{l}\text { DURATION OF } \\
\text { BREAST FEEDING } \\
\text { FOR YOUR FIRST } \\
\text { CHILD } \\
\end{array}$ & $\begin{array}{l}\text { DURATION OF BREAST } \\
\text { FEEDING FOR THE LAST } \\
\text { BUT ONE CHILD } \\
\text { (MONTHS) }\end{array}$ \\
\hline \multirow[t]{3}{*}{ AGE AT MENARCHE } & Pearson Correlation & .118 & .122 & .139 \\
\hline & Sig. (2-tailed) & .160 & .145 & .098 \\
\hline & $\mathrm{N}$ & 144 & 144 & 144 \\
\hline \multirow{4}{*}{$\begin{array}{l}\text { DURATION OF POST PARTUM } \\
\text { AMENORRHEA (PPA) AFTER THE } \\
\text { FIRST LIFE BIRTH (MONTHS) }\end{array}$} & & & & \\
\hline & Pearson Correlation & $.781^{* *}$ & .121 & $.348^{* *}$ \\
\hline & Sig. (2-tailed) & .000 & .150 & .000 \\
\hline & $\mathrm{N}$ & 144 & 144 & 144 \\
\hline \multirow[t]{3}{*}{$\begin{array}{l}\text { DURATION OF PPA AFTER LAST } \\
\text { BUT ONE LIFE BIRTH (MONTHS) }\end{array}$} & Pearson Correlation & 1 & $.170^{*}$ & $.364^{* *}$ \\
\hline & Sig. (2-tailed) & & .041 & .000 \\
\hline & $\mathrm{N}$ & 144 & 144 & 144 \\
\hline DURATION OF BREAST FEEDING & Pearson Correlation & $.170^{*}$ & 1 & $.511^{* *}$ \\
\hline
\end{tabular}




\begin{tabular}{|c|c|c|c|c|}
\hline VARIABLES & & $\begin{array}{l}\text { DURATION OF PPA } \\
\text { AFTER LAST BUT ONE } \\
\text { LIFE BIRTH } \\
\text { (MONTHS) } \\
\end{array}$ & $\begin{array}{l}\text { DURATION OF } \\
\text { BREAST FEEDING } \\
\text { FOR YOUR FIRST } \\
\text { CHILD } \\
\end{array}$ & $\begin{array}{l}\text { DURATION OF BREAST } \\
\text { FEEDING FOR THE LAST } \\
\text { BUT ONE CHILD } \\
\text { (MONTHS) } \\
\end{array}$ \\
\hline \multicolumn{5}{|l|}{ FOR YOUR FIRST CHILD } \\
\hline \multirow{6}{*}{$\begin{array}{l}\text { DURATION OF BREAST FEEDING } \\
\text { FOR THE LAST BUT ONE CHILD } \\
\text { (MONTHS) }\end{array}$} & Sig. (2-tailed) & .041 & & .000 \\
\hline & $\mathrm{N}$ & 144 & 144 & 144 \\
\hline & & & & \\
\hline & Pearson Correlation & $.364^{* *}$ & $.511^{* *}$ & 1 \\
\hline & Sig. (2-tailed) & .000 & .000 & \\
\hline & $\mathrm{N}$ & 144 & 144 & 144 \\
\hline
\end{tabular}

**. Correlation is significant at the 0.01 level (2-tailed).

*. Correlation is significant at the 0.05 level (2-tailed).

The table 10 confirms that there is a perfect positive correlation of 0.35 between the duration of postpartum amenorrhea (PPA) after the first life birth (months) and duration of breastfeeding for the last but one life birth (months) at $1 \%$ level of significance; it shows that there is also a relationship of 0.78 between duration of postpartum amenorrhea (PPA) after the first life birth (months) and duration of postpartum amenorrhea (PPA) after last but one life birth (months) at $1 \%$ level of significance, It shows that there is no relationship of 0.12 between the duration of postpartum amenorrhea (PPA) after the first life birth (months) and duration of breastfeeding for the first life birth (months). It also shows that there is no relationship of 0.12 between duration of postpartum amenorrhea (PPA) after the first life birth (months) and age at menarche.

It further shows a positive correlation of 0.17 between the duration of PPA after last but one life birth (months) and duration of breast feeding for the first life birth (months) at 5\% level of significance. It further shows a perfect correlation of 0.36 between duration of PPA after last but one life birth (months) and duration of breast feeding for the last but one life birth (months). It shows that there is also a perfect correlation of 0.51 between the duration of breast feeding for the first life birth (months) and duration of breast feeding for the last but one life birth (months) at $1 \%$ level of significance.

It shows no correlation of 0.12 between age at menarche and duration of PPA after the first life birth. It also reveals no correlation of 0.14 between age at menarche and duration of breast feeding for the last but one life birth (months).

\section{Conclusion}

The growing appreciation of the value of women education in Northern Nigeria is increasing but more has to be done concerning female child education, and so women education should be encouraged in order for them to know the importance of fertility rate control in the nation.

Women should be enlightened on the importance of family planning or child spacing because as more people choose family planning fertility falls and population growth slows. Although fertility has fallen throughout the world, further declines would make a crucial difference in many developing countries. World population has reached about 8 billion and is growing by nearly 80 million people each day. Slower population growth helps to protect the environment, it conserves resources, preserves clean air and water, eases pressure on cities and helps avoid conflict and most of all a slower population growth aids development, it buys time and with more population in their production years, provides a demographic bonus that can be invested in education, job creation, healthcare and other efforts to raise the living standards. For the women, it can open doors to education, employment and community involvement.

The sooner fertility falls to low level, the better most countries will be able to achieve sustainable development. Even small declines in fertility today will make a sustainable difference in population size in the future.

In demographic studies and with the physiological evidence suggesting that resumption of ovulation, and thus resumption of menses, depends on a particular hormonal balance, which in turn depends on sucking stimulus. It confirms the importance of breastfeeding in the resumption of menses. Most women are happy when they have longer period of amenorrhea, for this will prevent conception in the first six month postpartum. Yet because, mostly all mothers lactate their infants, still with the method of Lactation Amenorrhea Method (LAM) applied by them, the LAM users have a contraceptive method at hand that she can initiate herself when the LAM criteria no longer holds.

\section{References}

[1] Bongaarts, J. and H. Delgodo (1979). Effects of nutritional status on fertility in rural Guatemala.

[2] In: H. Leridon and J. Menken (end), Natural Fertility: Patterns and determinant of Natural Fertility, pp. 109-132. Liege, Belgium: Ordina Editions.

[3] Bongaarts, J. Potter, R. G. (1983). Fertility, Biology, and Behaviour: An Analysis of the proximate determinants. New York: Academic Press.

[4] Delgado, H., R. Martorell, E. Brineman, and R. E. Klein (1978). Nutrition, lactation, and Postpartum amenorrhea, American journal of clinical nutrition, 31: 322-327.

[5] Genezzani, A. D., F. Petraglia, R. Benatti, V. Montanini, I. Algeri, A. Volpe, and A. R. Genazzani (1991a). Luteinizing hormone (LH) secretory burst duration is independent from LH, Proclactin or gonadal plasma levels in amenorrheic women. Journal of Clinical Endocrinology and Metabolism 72: 1220-1225. 
[6] Genezzani, A. R., F. Petraglia, A. D Genazzani, G. Amato, G. D Ambrogio, S. Angioni, and B. Bidzinska (1991b). Perspectives on stress- induced amenorrhea. Pp. 321-326 in A. R. Genazzani, C. Nappi, F. Petraglia, and E. Martignoni (eds), stress and Related Disorders From Adaptation to Dysfuntion. Carnforth, UK: Parthenon publishing.

[7] Guz, D. and Hobcraft. J. (1991). Breastfeeding and fertility: A comparative Analysis. Population studies 45: 91-108.

[8] Howie, P. W., and A. S. McNeily (1982). Effects of breastfeeding patterns on human birth interval. Journal of Reproduction and fertility 65: 545-557.

[9] Jain, A. Hsu, T. C. Freedman, R. and Chang. M. C (1970). Demographic Aspects of Lactation and Postpartum Amenorrhea Demography 7: 225-271.

[10] John, A. M., J. A. Menken, and A. K. M. A. Chowdhury (1987). The effect of breastfeeding and nutrition on fecundity in rural Bangladesh: a hazards-model analysis. Population studies, 41: 433-446.

[11] Jones, R. E. (1990). The effect of initiation of child supplement on resumption of Postpatrum Menstruation. Journal of Biosocial Science, 22: 173-189.

[12] Jones, R. E. (1988). A hazards model analysis of breastfeeding variables and maternal age on Return to menses Postpartum in rural Indonesian women. Human Biology 60: 853-871.

[13] Lunn, P. G., M. Atkinson, and A. M. Prentice (1981). Maternal nutrition and lactational Amenorrhea. Lancet 1: 1428-1429.
[14] Loucks, A. B. (1990). Effects of exercise training on the menstrual cycle: existence and Mechanisms. Medicine and science in sports and exercise, 22: 275-280.

[15] Menken, J. (1979). Introduction. In: H. Leridon and J. Menken (eds.), Natural Fertility: patterns and determinants of natural fertility, pp 1-12. Liege, Belgium: ordinal Editions.

[16] Pirke, K. M., U. Schweiger, W. Lemmel, J. C. Drieg, and M. Berger, M. (1985). The influence of dieting on the menstrual cycle of healthy young women. Journal of clinical Endocrinology and metabolism, 60: 1174-1179.

[17] Popkin, B. M., D. K. Guilkey, J. S. Akin, L. S. Adair, J. R. Udry, and W. Flieger (1993). Nutrition, Lactation and birth spacing in Filipino women. Demography, 30 (3): 333-352.

[18] Salber, E. J., M. Feinleib, and B. Macmahon (1966). The duration of postpartum amenorrhea American Journal of Epideiology, 82: 347-358.

[19] Santow, G. (1987). Reassessing the contraceptive effect of breastfeeding. Population Studies, 41: 147-160.

[20] Van Ginneken, J. K. (1978). The impact of prolonged breastfeeding on birth intervals on postpartum amenorrhea. In: W. H Mosely (ed.), Nutrition and Human Reproduction, pp. 179-195. New York: Plenum Press.

[21] Wood, J. W., Lai, D., Johnson, P. L., Campbell, K. L. and Maslar, I. A. (1985). Lactation and birthspacing in Highland New Guinea. Journal of Biosocial Science, Supplement 9: 159-173. 